\title{
Teaching Competencies of Language Teachers in Research Universities in Beijing: Perspectives from SoTL and Institutional Theory
}

\author{
Yi Zhang ${ }^{1,2, * \mathbb{C}}$, Fugui Ye ${ }^{1}$ and Xiumei Liu ${ }^{2}$ \\ 1 Institute of Education, Tsinghua University, Beijing 100084, China; yefg@tsinghua.edu.cn \\ 2 Department of Foreign Languages, School of Law and Humanities, \\ China University of Mining and Technology, Beijing 100083, China; mayyameiliu@126.com \\ * Correspondence: lizze20@hotmail.com; Tel.: +86-138-1002-6254
}

Citation: Zhang, Y.; Ye, F.; Liu, X. Teaching Competencies of Language Teachers in Research Universities in Beijing: Perspectives from SoTL and Institutional Theory. Sustainability 2021, 13, 4943. https://doi.org/ $10.3390 /$ su13094943

Academic Editors: Jordi

Colomer Feliu and Naomi

T. Krogman

Received: 24 February 2021

Accepted: 25 April 2021

Published: 28 April 2021

Publisher's Note: MDPI stays neutral with regard to jurisdictional claims in published maps and institutional affiliations.

Copyright: (C) 2021 by the authors. Licensee MDPI, Basel, Switzerland. This article is an open access article distributed under the terms and conditions of the Creative Commons Attribution (CC BY) license (https:/ / creativecommons.org/licenses/by/ $4.0 /)$.

\begin{abstract}
Though professional development of language teachers has received increasing attention over the past decade, there is a lack of research on development of language teachers' teaching competencies in research universities. Informed by the institutional perspective and the framework of Scholarship of Teaching, this study investigates the development of 16 language teachers' teaching competencies in Beijing research universities. The findings show that language teachers' teaching competencies include English proficiency, professional ethics, pedagogical content knowledge, reflective thinking, and research-informed teaching. Factors influencing language teachers' teaching competencies range from the department level to the university level and the academia level. Pathways are proposed from the cultural-cognitive perspective, the normative perspective, and the regulative perspective to develop teaching competencies of language teachers.
\end{abstract}

Keywords: language teachers; teaching competencies; college English course; research universities

\section{Introduction}

Quality Education is one of the 17 Sustainable Development Goals proposed in 2015 by the UN as the core of its 2030 Agenda for Sustainable Development [1]. At the heart of this goal, a substantial increase of the supply of qualified teachers was set as a key target to be achieved by 2030 [2]. In the context of China's research universities, quality education endeavors to sustain two objectives: elite education and innovative research [3]. Research universities in Beijing have been doing well in achieving those objectives, as is indicated by their improved results in world university rankings in recent years. However, language teachers have not been given full credit for their contribution to the performance of those universities, since their strength in teaching and their contribution to the allaround competence of students are not justly acknowledged by the universities. This is evidenced by the fact that although an increasing number of Chinese university students are publishing in English in international academic journals [4], language teachers are frequently criticized for not producing as many research publications as academic staff from other disciplines [5,6]. They also face difficulties in getting further professional titles, since the appraisal system is largely based on academic production $[7,8]$.

In order to provide quality education as defined in the context of research universities, language teachers are eagerly involved in research. Language teachers have traditionally been focusing on teaching practice as language skills are the main contents of their courses, but they now realize the importance of integrating research into teaching practices [9]. The official plan of the College English Teaching Guidelines is the most important policy discourse on teaching English to non-English majors in China at the tertiary level. In its latest revision issued in 2020, professional development of language teachers was defined through five aspects: moral virtues, disciplinary content knowledge, pedagogical content knowledge, research ability, 
and information literacy [10]. In regard to research ability, the plan puts special emphasis on encouraging full-fledged research into language teaching, thereby adding a new dimension to language teachers' empirical knowledge of teaching competencies. This communicates a view of language teachers not only as classroom experts, but also as qualified members of an academic community who provide quality education to their students.

The objectives of this study are to explore the teaching competencies that language teachers need to have as educators in research universities in Beijing, and the underlying factors impacting the development of teaching competencies. This study focuses on a unique group of teachers, language teachers in research universities, who teach students across disciplines and majors, and whose experience of development in teaching competencies can be very different from other faculty members. Language teachers in this project refer to those who teach English primarily as a language to communicate in an educational setting to Chinese students. These language teachers teach a set of compulsory College English Courses. Given the size of the student population to which the course is offered, a language teacher's job is teaching-intensive [11]. As a language course, the College English Course does not carry disciplinary contents. Language teachers therefore differ from other faculties by the nature of their job. This research attempts to identify the key teaching competencies of language teachers as educators, and to explore the factors impacting the development of teaching competencies. Based on the results found from those two questions, we try to propose effective ways to nurture teaching competencies.

\subsection{Literature Review}

\subsubsection{Teaching Competencies of Language Teachers}

Recent studies on language teachers' teaching competencies reported several key themes. Feedback from Chinese researchers indicated that required abilities from university language teachers generally falls into five categories: dedication to teaching, structure of disciplinary knowledge, English as a Foreign Language (EFL) theoretical knowledge, abilities in technology, and life-long English learning [12-16]. However, studies on the factors that influenced the nurturing of teaching competencies showed that language teachers had a more complicated understanding of teaching competencies than of the above-mentioned categories. In the light of the national College English teaching reform, Qin Qiu [17] conducted discourse analysis of the College English Teaching Guidelines 2015 and pointed out that awareness of self-development in teaching, understanding the nature of EFL education, and developing expertise in research should also be included in the teaching competencies of language teachers. More recent research conducted in 26 provincial districts emphasized that language teachers need to further develop their research abilities, especially in the area of English language needs analysis [18]. Popular views on how to develop language teachers' teaching competencies proposed that language teachers need to take the initiative through a constructive way of building professional communities, and practicing reflective thinking along with autonomous teaching [19-21]. More specific proposals on developing teaching competencies through doing research were put forward by a few researchers [22-24], which stated that pedagogical content knowledge (PCK) should be a central concept in integrating teaching practice with teaching research. The literature therefore indicated a new feature of teaching competencies. Conventional understanding of teaching practices is moving towards one that is evidence-based, requiring expertise in teaching research from language teachers so that they make rational improvements on teaching practice based on research results. It seemed to show a stronger connection between theory and practice, and between academic knowledge and classroom teaching. Do language teachers in Beijing research universities value the expertise in research for improving language teaching? What teaching competencies do they value? This study investigates the competencies that language teachers need to have in order to practice effective teaching in research universities. 


\subsubsection{Application of Teaching Competencies}

Research on language teachers' pedagogical practices gave a description of how their teaching competencies were applied in a classroom setting. The most popular research theme was on new instructional models which clearly reflect the trend of online learning. A few years ago when the practices of flipped classroom and MOOC became popular, language teachers were among the first ones who tried to apply the new model in their classes [25-28]. More recently, online resources like SPOC were imbedded in College English teaching [29-31]. Last year, language teachers across the country all delivered online classes due to the outbreak of the pandemic. Extensive research was conducted on assessing the effects, problems, and instructional strategies of the large-scale online English teaching, and on establishing blended-learning as a regular instructional model [32-34]. Technology enhanced English teaching demands the competence to find, use, and create online resources [35]. But more than information literacy in itself, it means language teachers need to develop teaching competencies according to the circumstances where language teaching is situated [36]. To that end, this research investigates the factors that have an influence on teaching competencies.

Another popular research theme highlighted a discussion over the curriculum of the College English Course. The curriculum determined the teaching competencies language teachers must possess, in that it identified the knowledge required. Even though a nationally standardized curriculum of the course did not exist, College English teaching in universities nationwide followed similar patterns. Universities generally set their College English curriculums based on three aspects of consideration: English as a language for interpersonal communication, English as a tool for academic or workplace use, and English literature and culture as parts of a liberal arts education [37]. Most universities, however, focused on the first and the third aspects. They offered courses on English skills in listening, reading, writing, speaking, and translation; other commonly listed courses included cross-cultural communication and an introduction to British/American literature [38]. The curriculum setting in each university was largely grounded in its language teachers' instructional knowledge. As a good portion of language teachers were Chinese teachers who graduated from disciplines of Applied Linguistics, Foreign Literature, and Foreign Linguistics [39], language teachers conducted their classroom teaching with relatively solid language skills, systematic linguistic knowledge, as well as some knowledge of English and American literature and culture. However, they were not adequately capable of teaching English that entailed a particular context or genre [40]. The discussion on curriculum therefore was on the necessity for language teachers to acquire discipline-specific knowledge, and to teach such knowledge to their students for academic or professional use. This proposal echoes Hyland's conception on teaching English for specific purposes [41], and responds to Paltridge and Starfield's opinion on revising language teachers' knowledge structure in order to perform effectively in ESP (English for Specific Purposes) teaching [42]. The discussion, however, did not specify how language teachers could acquire such knowledge. Feasible pathways have not been proposed for language teachers to follow in order to restructure their teaching knowledge. Thus, the current research needs to take into account the effective ways of nurturing teaching competencies.

\subsection{Theoretical Framework}

In view of the research pattern of integrating teaching practice with teaching research as indicated by the literature, we try to analyze the structure of teaching competencies by drawing on the theory of Scholarship of Teaching and Learning (SoTL). By proposing the notion of Scholarship of Teaching, Boyer conceptualized four dimensions of scholarship: discovery, integration, application, and teaching [43]. Teaching was therefore considered as a form of scholarship because content knowledge can be organized and passed on to students more effectively with proper teaching methods. Shulman [44] went on to define SoTL as "systematic reflection on teaching and learning made public", which identified reflection - the investigation into student learning - as a form of research. Hutch- 
ings [45] further elaborated on how teaching practice could be integrated with research, thus approaching teaching from dual perspectives: the practice of teaching and research of teaching. McKinney [46] carefully clarified what the Scholarship of Teaching means by distinguishing it from the idea of scholarly teaching, so that the conceptualization of Scholarship of Teaching would not fall into the narrow understanding of teaching academic content. In order to explain the dual perspectives of Scholarship of Teaching, Richlin [47] constructed the process of generating theoretical knowledge from teaching practice through 10 developmental steps, and Paulsen [48] went on to refine this process by identifying pedagogical content knowledge (PCK) as the core concept in teacher knowledge. He proposed a model on the relationship of research and Scholarship of Teaching to explain how PCK connects teaching practice and teaching research. In this article, we analyze how language teachers understand their teaching competencies from the theoretical perspective, as is constructed above. The analysis is developed in three themes: relationship between practice and theory in language teaching; reflection as a process of researching teaching practice; PCK as the central knowledge which connects research with practice, and which also connects subject matter with pedagogy. In order to explore the factors influencing the development of teaching competencies, and to propose the paths for language teachers to develop teaching competencies, we interpret our data under Scott's [49] theoretical framework of institutions and organizations by drawing on the three pillars of institutions: regulative, normative, and cultural-cognitive.

\section{Materials and Methods}

\subsection{Context and Participants}

The research was based in 5 research universities in Beijing, China. All research universities included in this research are comprehensive universities, with two especially strong in science and engineering disciplines, and the other three in social sciences and humanities. According to the QS 2021 ranking of world universities, 2 of the universities were ranked in the top 50 globally, 1 university between 200 and 300, and 2 universities between 400 and 500. There were a total of 16 language teachers included in the research. Among them, four language teachers served as heads of College English teaching units while also working as classroom teachers. The other 12 language teachers had no managerial duties (Table 1). The teachers varied in terms of the highest degree they held or they were working on, the academic title they held, and in their stage of professional development (Tables 2 and 3). These variations might maximize the scope of the information obtained in this qualitative research.

Table 1. Distribution of the participants in 5 universities (Univ.).

\begin{tabular}{cccccc}
\hline & Univ. 1 & Univ. 2 & Univ. 3 & Univ. 4 & Univ. 5 \\
\hline Heads of teaching units & 1 & 0 & 1 & 1 & 1 \\
Regular teachers & 2 & 1 & 4 & 4 & 1 \\
\hline
\end{tabular}

Table 2. Stage of professional development.

\begin{tabular}{ccccc}
\hline & $<$ Years & 5-10 Years & 10-20 Years & $>$ 20 Years \\
\hline Language Teachers & 1 & 1 & 10 & 4 \\
\hline
\end{tabular}

Table 3. Degree and academic title statistics.

\begin{tabular}{ccccccc}
\hline & & Univ. 1 & Univ. 2 & Univ. 3 & Univ. 4 & Univ. 5 \\
\hline \multirow{2}{*}{ Degree } & Master's & 0 & 1 & 3 & 0 & 1 \\
& Ph.D. & 3 & 0 & 2 & 5 & 1 \\
\hline
\end{tabular}


Table 3. Cont.

\begin{tabular}{lcccccc}
\hline & & Univ. 1 & Univ. 2 & Univ. 3 & Univ. 4 & Univ. 5 \\
\hline \multirow{3}{*}{ Academic Title } & Assistant lecturer & 0 & 0 & 1 & 0 & 0 \\
& Lecturer & 1 & 1 & 2 & 3 & 1 \\
& Professor & 2 & 0 & 2 & 2 & 1 \\
\hline
\end{tabular}

\subsection{Research Instrument and Data Collection}

An exploratory qualitative design was adopted to investigate the structure of teaching competencies and to explore the factors that mediate the development of such competencies. Semi-structured individual interviews were used to collect data. "For one-on-one interviewing, the researcher needs individuals who are not hesitant to speak and share ideas" [50]. In order to elicit rich information from the participants, convenience sampling was used in the process of establishing contact with the interviewees. The interviewees were recruited for the research through acquaintances' recommendations. The interviews were based on outlines with 23 questions for regular teachers (Table 4), and 13 questions for head teachers of the language teaching units (Table 5). The questions covered three focal points: what are the most important teaching competencies for language teachers to possess; what factors influence the building of these competencies; and how can research universities nurture teaching competencies.

Table 4. Interview outline for regular language teachers.

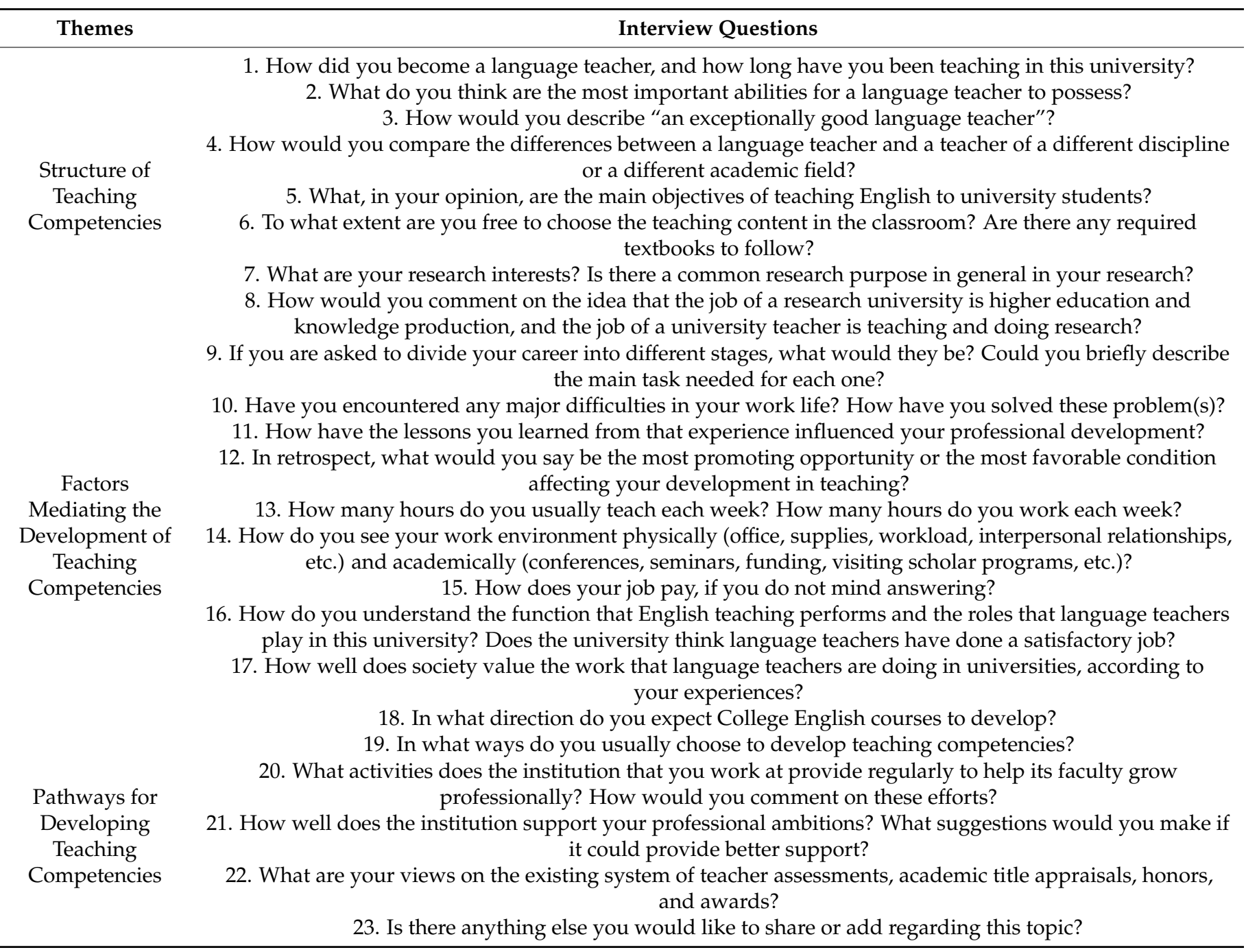


Table 5. Interview outline for head teachers of language teaching units.

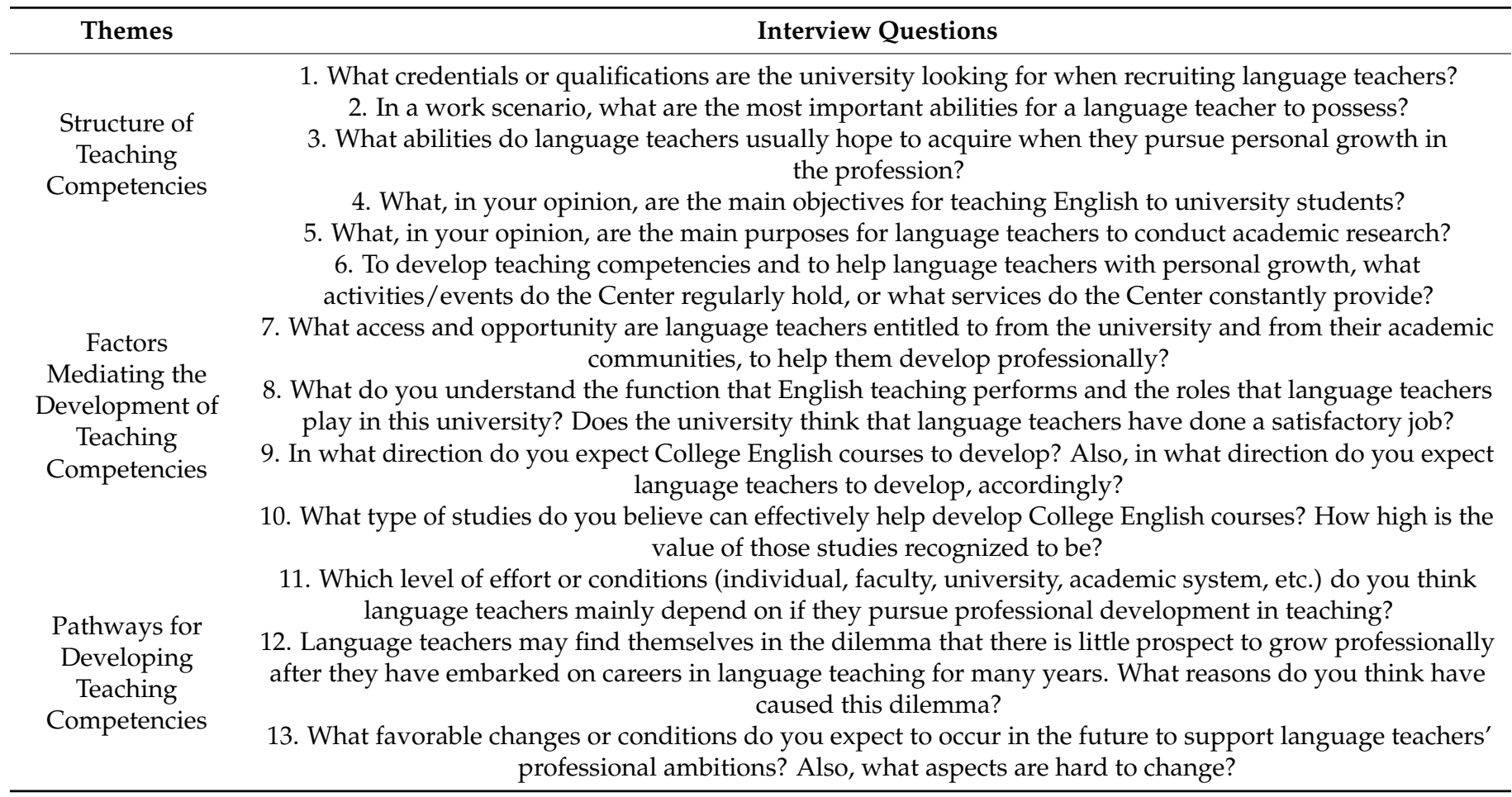

All of the interviews were conducted in Mandarin because the participants were expected to better express their ideas in their mother tongue [51]. The length of the interviews was approximately $90 \mathrm{~min}$. All but one of the interviews were audiotaped and transcribed into written texts. The one participant who refused audio recording was worried about the sensitive content disclosed in the interview, but did allow note-taking. Consent forms were signed before the interviews to show that they had agreed to take part in the research.

\subsection{Data Analysis}

Thematic analysis was used to analyze the interview data because of its theoretical flexibility in interpreting the various aspects of the research topic [52]. The interview data was composed of three parts: structure of teaching competencies, factors mediating the development of teaching competencies, and pathways of nurturing teaching competencies.

The data relating to the structure of teaching competencies was first analyzed in an inductive way because this aspect was underexplored. Based on readings and initial coding of the data regarding the structure of teaching competencies, the authors noticed several themes that could be identified with the notion of SoTL. For example, the codes "the ability to understand soft (basic) knowledge from another discipline", and "the ability to teach English literature/culture as liberal arts education" were categorized as "pedagogical content knowledge". The codes "reflection on the syllabus", and "reflection on how the students respond on the teaching materials" were categorized as "reflection as a form of research. The codes "student needs analysis", "research in second language acquisition (SLA)", and "rearranging the curriculum informed by research" were categorized as "rearranging teaching practice informed by research". Other themes that did not fall into the SoTL framework were categorized as candidate themes or sub-themes. Both the SoTL themes and the candidate themes were reviewed by judging whether they formed a coherent pattern [52]. A thematic map of the structure of teaching competencies was created (Table 6). The prevalence of each teaching competence was calculated by dividing the number of participants who mentioned the competence by the total population of the sample group. 
Table 6. Language teachers' views on the structure of teaching competencies.

\begin{tabular}{|c|c|c|}
\hline & Perceived Teaching Competencies & Frequency \\
\hline \multirow{3}{*}{ English proficiency } & Very good command of English & $100 \%(16)$ \\
\hline & Education/work experience in English-speaking countries & $100 \%(16)$ \\
\hline & First degree majoring in English & $75 \%(12)$ \\
\hline \multirow{4}{*}{ Professional ethics } & Putting students first & $75 \%(12)$ \\
\hline & Enthusiasm in teaching/Reliability & $94 \%(15)$ \\
\hline & Life-long learning/Adaptability & $100 \%(16)$ \\
\hline & Interpersonal skills and team spirit & $75 \%(12)$ \\
\hline \multirow{4}{*}{$\begin{array}{c}\text { Pedagogical } \\
\text { content knowledge }\end{array}$} & Teaching English literature/culture as liberal arts education & $56 \%(9)$ \\
\hline & Understanding basic knowledge from another discipline & $63 \%(10)$ \\
\hline & Teaching English language that students will use in further education or at workplace & $69 \%(11)$ \\
\hline & Education in an English-related or interdisciplinary background & $88 \%(14)$ \\
\hline \multirow{3}{*}{$\begin{array}{l}\text { Reflection as a } \\
\text { form of research }\end{array}$} & Reflecting on the syllabus & $50 \%(8)$ \\
\hline & Reflecting on teaching materials & $88 \%(14)$ \\
\hline & Reflecting on class management & $82 \%(13)$ \\
\hline \multirow{5}{*}{$\begin{array}{l}\text { Rearranging } \\
\text { teaching practices } \\
\text { informed by } \\
\text { research }\end{array}$} & Student needs analysis & $56 \%(9)$ \\
\hline & Rearranging the curriculum informed by research & $82 \%(13)$ \\
\hline & Conducting research in SLA & $44 \%(7)$ \\
\hline & Conducting research in language teaching pedagogy & $44 \%(7)$ \\
\hline & Doctoral degree & $88 \%(14)$ \\
\hline
\end{tabular}

The data relating to the factors that mediate the development of teaching competencies and to the pathways for nurturing teaching competencies was analyzed in a deductive way driven by the authors' interest in the interpretive power of Scott's new institutionalism theory. Subthemes, such as "the culture of recognizing the importance of language teaching", "university assessment policy" and "national guidelines on College English teaching" were mapped onto the institutional systems at different levels following Scott's theory.

\section{Results}

\subsection{Structure of Teaching Competencies}

Table 6 summarizes the teaching competencies that language teachers regarded as being important to possess. The teaching competencies can be categorized into five themes: English proficiency, professional ethics, pedagogical content knowledge, reflection as a form of research, and rearranging teaching practice as informed by research. The participants mentioned basic work requirements (English proficiency and work ethics) more frequently. Beyond that, the participants showed an inclination to integrate teaching practice with research (pedagogical content knowledge, reflection as a form of research, rearranging teaching practice informed by research). In the following text, the participants are identified according to the university they are from (with " $U$ " abbreviated from "university"), and the role they take in the English teaching units (with " $\mathrm{H}$ " abbreviated from "head teacher" and " $\mathrm{T}$ " abbreviated from "regular teacher").

\subsubsection{English Proficiency}

More than $75 \%$ of the participants stated that English proficiency was of obvious importance. They interpreted the acquisition of English proficiency from three angles: majoring in English, exposure to an authentic English-speaking environment, and an adequate command of English. Additionally, 12 participants believed that a first degree with a major in English was a pre-requisite, and all of the participants believed that language teachers should have had education or work experience in English-speaking countries.

U1H1: When we recruit language teachers, we require that they major in English in their undergraduate education if they are Chinese teachers of English. This is because this ensures solid knowledge of the language, the skills to use it properly, and understanding the English cultures in general. Compared to native speakers who teach English here, we think 
Chinese teachers with an English educational background show a better understanding of student learning, and we think this is because Chinese teachers once had similar learning experiences to those of the students now they teach.

U3T3: All of the language teachers here have the experience of studying or working in a major English-speaking country. I think this is very important for Chinese teachers because we are not native speakers of English. Actually, the language teachers working here have similar experiences in language training. Basically in undergraduate education, we majored in English. After that, some people went to English speaking countries for graduate education. The others stayed in China and got their master's in Applied Linguistics or English Literature. They might also have moved on to get a doctoral degree. But after we joined in this university and worked here, we were sure to have opportunities to go on visiting scholar programs to go abroad at some point.

All of the participants thought that an overall good command of English ensured a high capability in teaching English. This sub-theme overlapped with the two sub-themes reported above on some occasions. It differed from the other two sub-themes in that "very good command of English" emphasized the application of teaching competencies in classroom practice, while the other two were credentials in staff recruitment.

U2T1: I think a very good command of English is an obvious requirement. People may get this English proficiency in one way or another, with various educational backgrounds or experiences. But above all, this ability means we know what is good English and what is bad English. We also know how to improve English and how to learn it. Without this ability, we are not qualified to teach in an English class.

\subsubsection{Professional Ethics}

Professional ethics were perceived as a crucial quality for a competent language teacher by most participants. A total of 12 participants mentioned that "putting the students first" was the mindset they had in developing teaching competencies. They realized that their job was to "help the students grow in an all-around way", and they believed that students' growth was more important than their own opportunities for career development.

U4T2: We have a very heavy workload. I have $16 \mathrm{~h}$ of teaching each week this semester. Last winter I even taught over $20 \mathrm{~h}$ each week occasionally. Teaching and researching compete for time. I really do not have the time to research with this workload. Also, I will not get a promotion if I do not publish. But if you ask me which is more important, I choose to sacrifice my own career development, because helping the students grow is what this job really is for.

A total of 15 out of 16 participants reported that enthusiasm in teaching was a form of teaching competency because "how well we teach is decided by how much we put in teaching" (U3T2). Among the 15 participants who responded to enthusiasm, 4 were head teachers of the teaching units. They interpreted "enthusiasm" into "reliability" from a managerial perspective. They explained that the language teaching work required self-disciplines such as dedication, commitment, and endurance. Without enthusiasm in teaching, language teachers could hardly regulate themselves accordingly, and thus are "unreliable" (U1H1).

All of the participants reported life-long learning as being crucial for maintaining teaching competencies. They typically believed that language teachers were challenged by the improving English proficiency of the students, and by the fast development in the field of language teaching. Head teachers interpreted it as being equivalent to "adaptability".

"Interpersonal skills and team spirit" were mentioned by $75 \%$ of the participants. They reported that they had gained practical knowledge in teaching following colleagues' suggestions, or they had benefited from self-started PD groups.

\subsubsection{Pedagogical Content Knowledge}

Language teachers realized that expanding their personal knowledge scope was of great importance to teaching. Over 50\% of the participants reported that they were 
engaging in obtaining content knowledge from various fields in the hope of teaching that knowledge in their language classes, which could therefore be summarized as pedagogical content knowledge.

English literature/culture was reported as a type of content knowledge that had been traditionally taught in English classes. Language teachers were now facing the challenge of expanding their knowledge base into non-traditional fields of language teaching. They reported learning basic knowledge in the fields of Logic, Computer Science, Psychology, Theater, and Opera, among others. Another sub-theme that emerged repeatedly was "teaching English that the students will use in further education or at a workplace" is important. Specifically, it referred to English for Academic Purposes (EAP) and English for Special Purposes (ESP).

U4T1: I am convinced that language classes are evolving towards being content-based. The undergraduate students enrolled in this university are significantly more proficient in English than students from a decade ago. Most of them do not need language skills lessons. We, as language teachers, must teach English in a way that the students can use it as a tool to learn subject matter, or to communicate in their academic fields.

A total of 14 teachers mentioned "Education in English-related or interdisciplinary background" as a quality necessary for teaching English efficiently, though they also admitted that the current English-teaching faculty was not equipped with systematic interdisciplinary knowledge.

U5H1: In future teacher recruitment, we must consider having teachers from other disciplines to teach College English courses. We may recruit a teacher who was educated abroad in Electronic Engineering, for example. It is difficult to make this happen, though. This university only recruits people with a doctoral degree now. If this person graduated with a Ph.D. in EE, it would make no sense to teach language in this university. But anyway, I suppose an interdisciplinary educational background will be an important consideration.

\subsubsection{Reflection as a Form of Research}

Language teachers frequently reported reflection as an effective means of improving teaching practice. They considered reflection as a form of research because the process of reflecting generated new knowledge in guiding teaching practice. The most frequently accounted activities of reflection were revising the syllabus, revising the course materials, and reflecting on class management.

U5T1: College English is a collection of English language courses arranged in several modules. So we have many different courses and accordingly many syllabuses. We make adjustments and amendments to the syllabuses every four years. We make the revisions based on our reflection on teaching and on what we find in the past four years of teaching.

U4T4: Teaching competencies do not narrowly mean classroom teaching. You need to do tons of preparation before going to the classroom. You have to have the ability to develop course materials. That is what we have been doing in recent years. We remade all the course materials except course books on language skills. This process requires mixed abilities of reflecting on past teaching experiences, selecting materials in line with course objectives, and so on. I think this is a form of research, perhaps without a capital R.

\subsubsection{Rearranging Teaching Practice Informed by Research}

The participants mentioned two types of research. The first type was the research on topics in Linguistics or English Literature, which bore little relevance to College English teaching. The second type was the research closely or peripherally related to College English teaching. The second type included research in second language acquisition and in language teaching pedagogy, which was regarded as "conventional research" by the participants. The "unconventional research" reported by the participants was "student needs analysis" and "rearranging the curriculum informed by research". 
A total of 9 participants mentioned "student needs analysis" as a type of research. It ranged from small-scale research in one class, to large-scale research on students enrolled in the same year.

Also, 13 participants mentioned that they rearranged the College English curriculum based on research findings.

U3T3: We changed the whole College English curriculum last year. We now have different policies on teaching the course to students from different schools of the university. We made the arrangement based on statistics. According to the official reports of the university, $1 / 3$ of the undergraduates go abroad after they finish their four years of study here, $1 / 3$ of the undergraduates stay in China for graduate study, and still 1/3 of them go to the job market. So we designed the modules on academic reading and writing to cater to the students who will further their studies. We offer language skill lessons to cater to those who are going to find a job. They (the head teachers) also conducted a survey on us (the language teachers). We had a poll to vote on the candidate modules, and every one of us proposed to offer at least one course that we felt confident to conduct.

A total of $88 \%$ of sample teachers mentioned having a "doctoral degree" as being a necessity for effectively conducting research. Though some participants did not recognize the importance of a doctoral degree in classroom teaching of English, they identified its importance for systematic training in research methodology.

\subsection{Factors Mediating the Development of Teaching Competencies \\ 3.2.1. Cultural-Cognitive Factors}

Cultural-cognitive factors that had an influence on the development of teaching competencies were reported on two levels: the department level, and the university level.

At the department level, language teachers were strongly motivated to develop teaching competencies by the local culture of teaching excellence prevailing within the language teaching units. All of the participants associated the importance of improving teaching competencies with facilitating the growth of their students.

U4T2: I think my job is important. I can help the students with their all-round development. There is no doubt that every one of them needs English in their further development. I feel fulfilled when I think this way, and I think I can represent other language teachers here. Some very experienced language teachers are still very alert in teaching. They always carefully plan their lessons. I learned a lot when observing their classes.

At the university level, the culture of recognizing the importance of language teachers was ambiguous. Participants reported conflicting statements on the reputation of language teaching. Regular teachers from the sample frequently reported that they received negative feedback from the university about language teaching. Head teachers, in contrast, held a more positive view about the support from the university. The following are typical statements from regular teachers.

U3T4: The university sees us (language teachers) as a burden, because we do not produce as many publications as disciplinary teachers. They (university policy makers) seemed not to understand that our job is to teach, not to publish. But they cannot do without us either. Like I said, they need us to teach English. They just do not admit that we are important.

U5T1: I do not feel supported in developing teaching competencies from the university level. The Education Administration Office frequently gave judgements on our teaching. I have to say those judgements were very superficial, not touching on the content that we taught. They never encouraged us. Whenever there was a regular meeting inside the language teaching unit, there had to be some negative feedback from the Office. We really put a lot of effort in teaching. This is so frustrating, and annoying, too, if you heard that too much.

U4T4: I am afraid the disciplinary teachers see us as very unimportant in the university. They think the whole language teaching thing is not effective, if not downright useless. 
They think the English classes take up too much time for their students. Once I accompanied a professor from another department to go on a project meeting held abroad, and I was supposed to be his interpreter. Turned out he did not need me to translate at all. He got his doctor's degree from the US. Yes, he made minor mistakes in using English, and he has a strong accent. But he had no problem in communicating with foreigners, both for daily use and for exchanging ideas on the disciplinary stuff. Sometimes I doubt if it is necessary to have us in the university. We are trying very hard now to teach ESP courses. The professor I mentioned could do that effortlessly if he wants. We are teaching EAP courses. He can do that, too. He has got a long list of publications in English. He can teach English writing for publishing much more in depth than I can.

Head teachers showed optimism about the university's attitude.

U1H1: The language teaching unit is now an independent center from the English department. I think this obviously shows the determination of the university to develop language teaching. Honestly speaking, our unit was quite marginalized when it belonged to the English department. We now hope to develop language teachers in a way that will better serve the purpose of language teaching. I am sure that the university will support the center.

U5H1: We revised the College English curriculum. We did this because the university wanted us to put emphasis on promoting speaking abilities of the students. The university is hoping the students will have a stronger influence in the international arena, for example in international undergraduate mathematical modeling contests, or in model United Nations. We completely redesigned the curriculum. This required cooperation from the language teachers and strong support from the university because now we need more classrooms with upgraded hardware and advanced technology. We need more native English teachers. We also need to learn from experiences from other universities or even from other countries, so we need to send our teachers to those places. The university is supporting us in all the things I just mentioned.

\subsubsection{Normative Factors}

Normative factors that had an influence on the development of teaching competencies were reported at two levels: the university level and the academia level.

At the university level, participants reported not only favorable opportunities offered by their universities to promote teaching competencies, but also unfriendly treatment from universities. All of the participants mentioned that their universities regularly sent language teachers to go on academic programs, from domestically and abroad. These are typical accounts on the topic:

U2T1: The most favorable opportunity that helped me in developing teaching competencies was when I went to the US on a Fulbright program. My program was on language teaching, and I stayed there for one year. That program provided adequate chances for me to have a comprehensive understanding of the American language and culture. Language teachers in the teaching unit have all been on similar programs. There are lots of opportunities.

U4T3: There are regular programs that language teachers can apply for if we want to. We can attend training courses provided by the Foreign Language Teaching and Researching Press. We can apply for visiting scholar programs with the China Scholarship Council. Some colleagues attended a course on language teaching pedagogy in Singapore. Also, all of the language teachers here went together to the UK during summer breaks in the last two years for a set of courses in language teaching practice and theory. Their pay was all covered by the university.

An unfavorable aspect was reported regarding the appraisal system. Most language teachers in the sample held teaching positions. Only a few of them held positions with both teaching and research duties. However, all of the language teachers were appraised by similar standards with minor variances. The participants all mentioned that research was given far more weight than teaching outcomes when appraising teachers. 
U3T2: It is very very difficult for language teachers to achieve a higher academic title. The university looks at research publications and grants only. There are certain requirements on teaching performance if you apply for a promotion in academic titles, but the conditions are very easy to meet. Language teachers do enjoy lower standards in publishing requirements than disciplinary teachers, because we are in teaching positions. But the standards are still too high to meet. It is too hard for us to publish so many works with the heavy workload in teaching. Also, it seems the university will not revise the appraisal system. It is understandable, though because publications are easy to be quantified, but teaching is not.

At the academia level, the participants frequently mentioned the difficulty in publishing research papers in language teaching. They stated that their universities required them to publish in academic journals indexed by the Chinese Social Sciences Citation Index (CSSCI). However, the indexed journals seldom accepted articles based on language teaching practices.

\subsubsection{Regulative Factors}

Regulative factors that have an impact on the development of teaching competencies were reported to focus on the national language teaching and learning policies.

The series of College English Teaching Guidelines was the policy document most frequently mentioned by the participants. It states the objectives, curriculums, evaluation, and management of College English teaching. The Guidelines, periodically issued by the Ministry of Education (MOE), acted as regulative policies for the implementation of College English teaching. The formulation of the Guidelines was contextualized in a broader vision of talents cultivation at the tertiary level of education. Specifically, the participants cited the Outline of National Educational Development Plan, a regulatory document on the goals of education from the year 2010 to 2020, to explain the teaching objectives of the College English Course, and the requirement on teaching competencies in accordance with the objectives. The participants also discussed the localized interpretations of the Guidelines in their universities, which involved customizing the Guidelines to better suit the needs of their students. They justified their interpretations according to the national policies on supporting the development of "First-class" research universities and "Firstclass" disciplines, which is a national initiative of higher education development proposed in 2016.

In addition, the participants also reported that national policies for language teacher preparation were influential regulative factors. They expressed their concerns regarding equipping language teachers with disciplinary content knowledge.

U4T1: Language teachers are now expected to teach ESP classes, but I do not see that happening very soon. We need time to equip ourselves with such knowledge. We do not have the capacity to teach subject matter in English right now. This is because we were not educated that way. We did not learn any subject content in another discipline. I would suggest that universities should add some introductory courses from other disciplines to the curriculum for English majors in undergraduate education. I think this is especially important in pre-service teacher education. For example, a student majoring in English should also take courses in biology for four years, or even longer. In this way, s/he would graduate with interdisciplinary knowledge. S/he would have a solid understanding of biology plus English proficiency.

\section{Discussion}

This study offers an analysis of the structure and influential factors of teaching competencies among language teachers in Beijing research universities. It represents a concern about the professional development of teachers holding teaching-intensive posts in research universities. Through this analysis, it provides evidence to confirm that the structure of teaching competencies is affected the research ability of language teachers in research uni- 
versities. In addition, it also summarizes the factors mediating the development of teaching competencies based on the aspects of culture and cognition, norms, and regulations.

\subsection{Structure of Teaching Competencies}

Language teachers in research universities generally held that English proficiency was the primary requirement needed to work as a language teacher. Educational background was considered as one of the necessary credentials to work as a language teacher. Perhaps notable was what was missing in the participants' responses to English proficiency. First, teaching experience was not required for a post so teaching-intensive as language teaching does. The language instructors typically had no formal teaching experience before joining the universities. Novice teachers were required to attend lectures on a general topic of higher education organized by education administrative offices, but no real-life teaching practice was included. Second, language teaching qualifications were not required. Many of the teachers had not heard of second/foreign language teaching certificates such as CELTA (Certificate in English Language Teaching to Adults), TEFL (Teaching English as a Foreign Language), etc. This finding indicated that qualifications and credentials, including educational background, teaching experiences, and language teaching certificates, need to be specified by research universities in order to ensure teaching proficiency of language teachers.

Professional ethics were reported as important teaching competencies. Language teachers attached great importance to professional ethics in maintaining enthusiasm in teaching, engaging in life-long learning, putting the students first, and working in teams in order to benefit from colleague support. The result confirmed the findings of Kafi [53] who reported commitment to profession as well as learners as crucial professional ethics of EFL university instructors. The result of identifying the importance of students confirmed the findings of Ramesh [54] who reported a positive attitude towards students as the strongest competency of the faculty members. The finding of life-long learning as a teaching competency confirmed Sahan's [55] conclusion that life-long learning tendencies predicted teaching-learning process competencies. The finding on teaching support from course teams strengthened Guo and Xu's [21] argument on the benefit of professional teaching communities amongst language teachers.

Pedagogical content knowledge was found to be important as the knowledge base of teaching competencies. PCK was specified in five domains by language teachers: English literature or culture, basic disciplinary knowledge from another subject, EAP and ESP knowledge, and interdisciplinary educational experiences. The findings presented here echoed Gomez's [56] study on the interrelations of various types of knowledge which contributed to in-service EFL teachers' pedagogical content knowledge. While Paulsen [48] proposed that PCK acted as a linkage between teaching practice and research, language teachers in this study did not explicitly state how the five domains of PCK could help in designing research into language teaching practices. Their understanding of PCK tended to arise from the students' side in the sense that it catered to students' needs for English skills in further education and at the workplace. The finding was therefore in line with Cai's [40] proposal, where he reached the conclusion of the need for changing language teachers' structure of knowledge based on student needs analysis. The similarity between the findings of this study and Cai's with respect of PCK showed that understandings of PCK among China's language teachers needed to be further deepened in PCK's implications for doing research.

Reflection was reported an important form of research. The role of reflective teaching was presented in a way that could possibly connect teaching practice with teaching research Research on course syllabuses, teaching materials, and class management were reported being carried out through reflection. Reflection took on the features of research when language teachers deepened their understanding of their teaching practices. The finding could be supported by Kalantari and Kolahi [57], who argued that experienced EFL teachers 
might adjust their teaching plans based on the students' needs and the context, and also consider the effectiveness of their teaching.

Language teachers reported an increasingly significant role that research took in rearranging teaching practices. Research was considered important to inform language teaching practice in four areas: student needs analysis, curricular rearrangements, second language acquisition, and language teaching pedagogy. Furthermore, a doctoral degree was also considered important, as it predicted proficiency in research methodology. These findings were supported by Yan et al.'s [58] research results conducted amongst female mid-career EFL teacher educators at regional teacher education universities in China, where they reported a lack of research competence in the aspect of research methods. While they reported their participants' acknowledgement in the meaning of research and its usefulness in teaching, which was similar to the findings of this study, this study furthered their research findings in specifying the ways that language teachers could use to transfer research theory into practical knowledge. This actual linkage between research and teaching seemed to narrow the gap captured as "two worlds" by Gomm and Hammersley [59] in explaining the difference between researchers and teachers.

\subsection{Factors Mediating the Development of Teaching Competencies}

Cultural-cognitive factors were reported in this study at the department level and the university level. At the department level, the local culture of commitment to teaching strongly motivated the language teachers to foster teaching competencies. However, recognition of the importance of language teaching was ambiguous at the university level. On the one hand, regular teachers considered that universities failed to recognize the value of language teachers. On the other hand, head teachers of the teaching units maintained contradictory views from those of the regular teachers. This could result from the fact that while head teachers received comprehensive feedback from the universities, regular teachers had limited sources of information from those same universities. This indicates that leaders at various levels could promote the culture of teaching excellence to encourage enthusiasm and energy in language teachers. Similar views were shared by Chen's [60] recent study on weaving SoTL into a university's teaching and learning culture.

Normative factors were reported at the university level and the academia level. Language teachers gave both positive and negative accounts regarding institutional support from their universities. Language teachers valued the importance of in-service training financially supported by the universities. A tendency could be observed by scrutinizing the language teachers' accounts that most of the programs mentioned were research-related training, which reflected the stance of the research universities. It showed that research universities would provide funding for their language teachers to promote teaching by engaging in research activities. Narratives of unfavorable treatment from universities focused on the appraisal system. Language teachers found it difficult to meet the standards they were appraised against with respect to publications. Combining the aforementioned favorable and unfavorable conditions, it can be found that research universities' attitude towards language teachers was consistent in encouraging research-based teaching. This attitude, however, was problematic. For one thing, at the academia level, China's academic journals were not eager to publish research in teaching practices. For another, although the nature of a teaching post required expertise in teaching, along with the time devoted to teaching, the nature of a research university put language teachers in a dilemma that teaching and research competed for time and effort from the teachers. However, once language teachers could balance teaching and research, they were very likely to develop into research experts in the field of teaching. In that case, teaching practice could increasingly benefit from teaching research.

Regulatory factors were reported to focus on national policies on language learning and teaching, and on teacher preparation. This focus on national educational policies reflected the top-down influence of educational governance. The finding partially confirmed Cheng and Wei's [61] research results on the predominant status of the English 
education policy National College English Teaching Guidelines. This study supplemented their findings with the influence of national policies on higher education and on research universities. In addition, policies on language teacher preparation were considered influential in developing teaching competencies. Language teachers referred to a lack of interdisciplinary content knowledge due to a single-disciplinary curriculum for English majors. A combination of English and another subject in curriculum design was proposed to foster interdisciplinary knowledge among pre-service language teachers. The interdisciplinary education was expected to aid language teachers in teaching ESP courses. Embedded designing was proved to be effective in improving pre-service teachers' PCK in Lancaster and Bain's [62] research on Australian pre-service teachers. By integrating evidence-based practice into university courses, pre-service teachers' PCK was improved. Their research focused on the pedagogical practice of PCK. Likewise, findings from this study indicated that content knowledge could possibly be proven effective in improving pre-service teachers' PCK with similar embedded designing of university courses.

\subsection{Pathways of Developing Teaching Competencies}

Based on the findings and discussion of the research, we seek to propose how research universities can develop language teachers' teaching competencies.

Cultural-cognitive elements in a higher education context is the culture of a university and shared understanding among its faculty. Language teachers will stop being alienated in research universities only when the culture of these universities clearly acknowledges the importance of language teachers. If research universities would recognize language teachers' contribution to students' competitiveness in a globalized educational context, staff from all disciplines would then believe that they should respect language teachers for their work. If research universities could see it as a shared logic that language teaching is a unique field of knowledge, which naturally produces less research output than other academic fields, language teachers would feel more fulfilled and have a clarified aim in their work.

Normative elements in research universities are rules that university staff comply with, and values and standards they are assessed by. It is important for research universities to set reasonable standards to appraise language teachers. While research output can be easily quantified, the evaluating teaching performance can be very subjective, and thus is seen as being unreliable. Research universities should design an adaptive appraisal system to meet the needs of staff from across disciplines. Academic journals should start to include research articles on teaching practices to facilitate the exchange of pedagogical knowledge in teaching subject matter.

Regulatory elements are the monitoring or sanctioning instruments enforced by laws and policies. In an educational setting, language education regulations serve as guidance when teaching English. In this context, research universities need to show great foresight and carefully design language education policies in accordance to their own objectives of English teaching and learning. Interdisciplinary courses need to be properly designed and included in teacher preparation education.

\section{Conclusions}

The findings of this study can be concluded to cover three areas. First, language teachers' teaching competencies include English proficiency, professional ethics, PCK, reflective thinking, and research-informed teaching. Second, factors influencing language teachers' teaching competencies range from the department level to university level and onto the academia level. Third, research universities need to set an array of paths that form a continuum, ranging from conscious regulations to unconscious conventions. Given the institutional support from all three levels, language teachers will enjoy a more dynamic interplay between teaching practice and research, therefore better serving the objectives of research universities regarding quality education. Education enables upward socioeconomic mobility [1] which promises a sustainable future, and quality education required by 
research universities in Beijing shares the same aim at its core [3]. In particular, developing teaching competencies of language teachers could help in achieving the aim of a quality education grounded in greater expectations of sustainability.

In this study, we try to analyze teaching competencies from the view of Scholarship of Teaching. Even though the Scholarship of Teaching is often regarded more as a conception than a framed theory, it provides a perspective for understanding teaching from a theoretical framework. It also allows teachers, as reflective practitioners, to inquire regarding the process of teaching and learning from their own empirical knowledge. We find it very meaningful to entitle teachers to reflect on how to teach, and on how to develop teaching competencies. We therefore used the view of Scholarship of Teaching suitable as an analytical instrument for this study.

There are two limitations regarding the research. First, in spite of the rich data obtained by the interviews, it might be risky to rely on the sole method to capture the participants' views, which might be influenced by the topic of the interview and the research questions in the outlines. It is suggested that future research should adopt multiple methods, such as long-time observation of language teachers' day-to-day work, to triangulate the data. Second, due to a lack of interview opportunities, the authors were not able to reveal the thoughts of university policy makers, who are also key stakeholders in developing teaching competencies of language teachers. Future research may interview university policy makers regarding the roles that language teachers and English teaching play, and regarding the place where language teachers fit in the education system in research universities.

Author Contributions: Conceptualization, Y.Z.; methodology, Y.Z.; software, Y.Z.; validation, F.Y.; formal analysis, Y.Z.; investigation, Y.Z.; resources, X.L.; data curation, F.Y.; writing-original draft preparation, Y.Z.; writing-review and editing, Y.Z., F.Y. and X.L.; visualization, Y.Z.; supervision, F.Y.; funding acquisition, X.L. All authors have read and agreed to the published version of the manuscript.

Funding: This research was funded by FUNDAMENTAL RESEARCH FUNDS FOR THE CENTRAL UNIVERSITIES, grant number 2021YQWF04 and by SHANGHAI FOREIGN LANGUAGE EDUCATION PRESS (SFLEP) RESEARCH PROJECT, grant number 2018BJ0026A. The APC was funded by China University of Mining and Technology (Beijing).

Institutional Review Board Statement: Not applicable.

Informed Consent Statement: Informed consent was obtained from all subjects involved in the research.

Data Availability Statement: The data presented in this study are available on request from the corresponding author.

Conflicts of Interest: The authors declare no conflict of interest.

\section{References}

1. United Nations. The Sustainable Development Goals Report. 2020. Available online: https://unstats.un.org/sdgs/report/2020 /The-Sustainable-Development-Goals-Report-2020.pdf (accessed on 15 April 2021).

2. United Nations. Quality Education. Available online: https://www.un.org/sustainabledevelopment/education/\#tab-bec3d6b2 e412d024e05 (accessed on 15 April 2021).

3. Ma, W.; Yun, Y. Internationalization for quality in Chinese research universities: Student perspectives. High. Educ. 2015, 70, 217-234. [CrossRef]

4. Cai, J. On the role of College English teaching in the national construction of World-class Universities and First-class Disciplines. Foreign Lang. China 2018, 15, 19.

5. Ma, T. On the teaching responsibility of university faculty. J. High. Educ. 2008, 29, 20-25.

6. Gu, P.; Gu, H.; Tao, W. A study of the context of university EFL teachers' professional development through narrative frames. J. PLA Univ. Foreign Lang. 2014, 37, 51-58.

7. Xia, J. Concerns about college EFL teachers' professional development problems and way-out in the new Chinese context. FLLTP 2012, 2, 6-8.

8. Zeng, J.; Qiu, M. The characteristic of evaluation and appointment of faculty professional title in current Chinese university: Based on professional title evaluation rules of twenty 985 project universities. Mod. Educ. Manag. 2016, 10, 73-80. 
9. $\mathrm{Xu}, \mathrm{J} . ;$ Lei, P. A narrative study on teaching-researching integration in College English teachers' professional development. Foreign Lang. China 2020, 17, 62-68.

10. Ministry of Education. College English Teaching Guidelines; Higher Education Press: Beijing, China, 2020.

11. Jiang, X. A review of the research on the job burnout of Chinese college English teachers and its implications. Foreign Lang. Educ. 2019, 3, 76-84.

12. Li, B. Building College English faculty in the context of educational informationization. Educ. Vocat. 2016, 17, 73-75.

13. Wang, Y.; Ding, H. College English teaching reform and paths for faculty development. Contemp. Educ. Sci. 2016, 16, 78-80.

14. Rui, Y. A study of teaching practice of College English teachers in perspective of observation at class. Theory Pract. Educ. 2016, 34, 34-36.

15. Si, B. On autonomous teaching abilities of College English teachers in IT_based environment. Foreign Lang. Teach. 2016, 37, 61-65.

16. Chen, L. College English teaching in the context of higher education internationalization. J. Chin. Soc. Educ. 2018, 1, 137-139.

17. Qin, Q. College English teaching reform and promotion of teachers' competence. Jiangsu High. Educ. 2016, 5, 68-71.

18. Zhang, W.; Guo, Q.; Wu, S.; Zhang, H. Status quo of and reform proposals for English education in China. Foreign Lang. China 2017, 14, 18-26.

19. Lu, P. Research on reflective teaching practice in College English teaching. Theory Pract. Educ. 2016, 36, 60-61.

20. Jiang, F.; Si, B. The Multi-dimensional research into information and technology-based College English teachers' autonomous teaching abilities. Foreign Lang. Res. 2017, 34, 53-59.

21. Guo, Y.; Xu, J. Impact of professional teaching communities on developing foreign languages teachers' teaching abilities. J. PLA Univ. Foreign Lang. 2016, 39, 104-112.

22. Chen, X. Narrative construction of PCK among College English teachers. Dongjiang J. 2013, 30, 105-110.

23. Yang, X. Research on College English teachers' teaching development from the perspective of PCK. Educ. Explor. 2016, 10, 108-110.

24. Liang, Y. PCK: The bridge between the development of teachers' conceptions of teaching and the development of their teaching behavior. Educ. Sci. 2011, 5, 54-59.

25. Zhai, X.; Lin, L. Factor analysis of Chinese learners' satisfaction in Flipped Classroom Model teaching. China Educ. Technol. 2014, 4, 104-109.

26. Zhao, N. Application of Flipped Classroom Model on College English teaching. Shandong Soc. Sci. 2015, S2, 351-352.

27. Wang, S. A study of college EFL learners' acceptance towards Flipped Classroom. Mod. Educ. Technol. 2014, 24, 71-78.

28. $\mathrm{Hu}, \mathrm{J}$;; $\mathrm{Wu}, \mathrm{Z}$. An empirical study on the MOOC-based college English Flipped Classroom instructional model. Technol. Enhanc. Foreign Lang. Educ. 2014, 6, 40-45.

29. Lv, T.; Wang, N. A study on the establishment and effect of the Flipped Classroom mode for SPOC+ teaching resource platforms as applied in College English teaching. China Educ. Technol. 2016, 5, 85-90.

30. Yang, X. On the construction and influencing factors of SPOC-based College English teaching model. Foreign Lang. Lit. 2019, 35, 146-154.

31. Jiang, Y.; Hu, J. A study on the large-scale instruction mechanism of SPOC-based College English flipped classroom. Technol. Enhanc. Foreign Lang. Educ. 2018, 4, 9-15.

32. Luo, X.; Ma, W. A practical research of online teaching of College English after the outbreak of COVID-19 pandemic. Technol. Enhanc. Foreign Lang. Educ. 2020, 3, 30-35.

33. Tan, X.; Fu, Y. Factors affecting online English learning satisfaction and continuous learning intention of college students. Technol. Enhanc. Foreign Lang. Educ. 2020, 4, 82-88.

34. Liu, J.; Wang, X. Effects of blended teaching of English audio-visual \& speaking course in the Internet Plus environment. Technol. Enhanc. Foreign Lang. Educ. 2020, 6, 105-112.

35. Ying, J.; Ning, Q. Research on the integrated mode of cooperative learning and autonomous learning in the blended teaching of College English. Theory Pract. Educ. 2019, 39, 45-47.

36. Wang, W. Contradiction between Change and Unchange of teaching philosophy and behavior in College English teaching. Contemp. Educ. Cult. 2020, 12, 81-88.

37. Tu, G.; Hu, D.; Fan, L. Reflections on the construction of new College English curriculum setting system. Foreign Lang. Educ. 2016, 13, 4-9.

38. Zheng, D. A multicurricular system of college English based on learners' needs analysis. Foreign Lang. World 2016, 6, 49-56.

39. Jiang, X.; Wang, X. Review and prospect of research on foreign language teacher knowledge in China. Foreign Lang. World 2016, 6, 31-39.

40. Cai, J. Upgrading College English teachers' knowledge structure. Technol. Enhanc. Foreign Lang. Educ. 2020, 1, 65-70.

41. Hyland, K. Specificity revisited: How far should we go now? Engl. Specif. Purp. 2002, 4, 385-395. [CrossRef]

42. Paltridge, B.; Starfield, S. The handbook of English for Specific Purposes; John Wiley and Sons: Hoboken, NJ, USA, 2013.

43. Boyer, E.L. Scholarship Reconsidered: Priorities of the Professorate; The Carnegie Foundation for the Advancement of Teaching: Stanford, CA, USA, 1990.

44. Shulman, L. Definitions of the Scholarship of Teaching and Learning (SoTL). Available online: http:/ / www.sotl.illinoisstate.edu/ downloads / definingSoTL.pdf (accessed on 22 February 2021).

45. Hutchings, P.; Shulman, L. The Scholarship of Teaching: New elaborations, new developments. Change 1999, 31, 10-15. [CrossRef] 
46. McKinney, K. Attitude and structural factors contributing to challenges in the work of the Scholarship of Teaching and Learning. New Dir. Inst. Res. 2006, 129, 37-50.

47. Richlin, L. Scholarly Teaching and the Scholarship of Teaching. New Dir. Teach. Learn. 2001, 86, 57-68. [CrossRef]

48. Paulsen, M.B. The relation between research and the Scholarship of Teaching. New Dir. Teach. Learn. 2001, 4, 20. [CrossRef]

49. Scott, R.W. Institutions and Organizations: Ideas, Interests, and Identities, 4th ed.; SAGE Publications: Thousand Oaks, CA, USA, 2013; pp. 55-71.

50. Lincoln, Y.; Guba, E.G. Naturalistic Inquiry; Sage Pubns: Beverly Hills, CA, USA, 1985.

51. Creswell, J.W. Qualitative Inquiry and Research Design, 2nd ed.; Sage Publications, Inc.: Thousand Oaks, CA, USA, 2007 ; p. 143.

52. Braun, V.; Clarke, V. Using thematic analysis in psychology. Qual. Res. Psychol. 2006, 3, 77-101. [CrossRef]

53. Kafi, Z.; Motallebzadeh, K.; Ashraf, H. Developing, localizing \& validating code of professional ethics through PLS-SEM: EFL university instructors' perspectives. Cogent Educ. 2018, 5, 1-23.

54. Ramesh, P.; Thammi Raju, D.; Reddy, K.M.; Krishnan, P.; Biswas, A.; Umamaheshwari, T. Perception of teaching competencies by administrators, faculty and students of Indian agricultural universities: An assessment of faculty training needs. J. Agric. Educ. Ext. 2019, 25, 337-359. [CrossRef]

55. Sahan, H.H. The relationship of prospective teachers' educational philosophy and life-long learning tendencies to their teachinglearning process competencies. Pegem J. Educ. Instr. 2020, 10, 1325-1367.

56. Gomez, J.C. Development of EFL teachers' pedagogical content knowledge through action research in a master's program. Probl. Educ. 21st Century 2020, 78, 533-553. [CrossRef]

57. Kalantari, S.; Kolahi, S. The relationship between novice and experienced EFL teachers' reflective teaching and their burnout. JPCC 2017, 2, 169-188. [CrossRef]

58. Yan, C.; He, C.; Guo, X.; Wang, J. Plateauing of Chinese female mid-career EFL teacher educators at regional teacher education universities. Prof. Dev. Educ. 2020, 4, 1-12.

59. Gomm, R.; Hammersley, M. Research and practice: Two worlds forever at odds? In Educational Research: Policy Making and Practice; Hammersley, M., Ed.; Paul Chapman Publishing: London, UK, 2002; pp. 59-82.

60. Chen, C.J. SoTL enculturation guided by Kotter's model of change. Int. J. Acad. Dev. 2021. [CrossRef]

61. Cheng, J.; Wei, L. Individual agency and changing language education policy in China. Curr. Issues Lang. Plan. 2021, 22, 117-135. [CrossRef]

62. Lancaster, J.; Bain, A. Designing university courses to improve pre-service teachers' pedagogical content knowledge of evidencebased inclusive practice. Aust. J. Teach. Educ. 2019, 44, 51-65. [CrossRef] 